Cite this: Phys. Chem. Chem. Phys., 2013, 15, 12147

Received 15th February 2013, Accepted 2nd May 2013 DOI: $10.1039 / \mathrm{c} 3 \mathrm{cp} 50710 f$

www.rsc.org/pccp

\title{
In situ spectroscopic investigation of oxidative dehydrogenation and disproportionation of benzyl alcohol $\dagger$
}

\author{
Ewa Nowicka, ${ }^{a}$ Jan P. Hofmann, ${ }^{\text {b }}$ Stewart F. Parker, ${ }^{\mathrm{c}}$ Meenakshisundaram Sankar, ${ }^{\mathrm{b}}$ \\ Giacomo M. Lari, ${ }^{a}$ Simon A. Kondrat, ${ }^{a}$ David W. Knight, ${ }^{a}$ Donald Bethell, ${ }^{d}$ \\ Bert M. Weckhuysen ${ }^{b}$ and Graham J. Hutchings*a
}

\begin{abstract}
In the solvent free oxidation of benzyl alcohol, using supported gold-palladium nanoalloys, toluene is often one of major by-products and it is formed by the disproportionation of benzyl alcohol. Gold-palladium catalysts on acidic supports promote both the disproportionation of benzyl alcohol and oxidative dehydrogenation to form benzaldehyde. Basic supports completely switch off disproportionation and the gold-palladium nanoparticles catalyse the oxidative dehydrogenation reaction exclusively. In an attempt to provide further details on the course of these reactions, we have utilized in situ ATR-IR, in situ DRIFT and inelastic neutron scattering spectroscopic methods, and in this article we present the results of these in situ spectroscopic studies.
\end{abstract}

\section{Introduction}

Supported bimetallic catalysts have received considerable attention because of their enhanced catalytic activities compared to their monometallic analogues, due to a synergistic effect that has been observed between the two metals. ${ }^{1,2}$ They have been reported as efficient catalysts with superior selectivity and/or stability for a variety of reactions including selective oxidation, ${ }^{2-5}$ hydrogenation/hydrogenolysis, ${ }^{6-8}$ direct synthesis of hydrogen peroxide ${ }^{9,10}$ and many more. ${ }^{1,11}$ Selective oxidation of benzyl alcohol to benzaldehyde is one of the most studied reactions because of the potential applications of benzaldehyde as an intermediate in the production of fine chemicals and fragrances. ${ }^{12-15}$ Achieving high selectivity to benzaldehyde has been a long term objective for this reaction. Designing catalysts to achieve high selectivity needs detailed knowledge about the origin and mechanism of the formation of by-products. Recently, we reported that $1 \% \mathrm{AuPd} / \mathrm{TiO}_{2}$, prepared by a sol immobilization method, is a catalyst for the solvent-free

\footnotetext{
${ }^{a}$ Cardiff Catalysis Institute, School of Chemistry, Cardiff University, Cardiff, CF10 3AT, UK. E-mail: hutch@cardiff.ac.uk; Fax: +44 (0)2920-874-030

${ }^{b}$ Inorganic Chemistry and Catalysis, Debye Institute for Nanomaterials Science, Utrecht University, 3584 CG Utrecht, The Netherlands

${ }^{c}$ ISIS Facility, STFC Rutherford Appleton Laboratory, Chilton, Didcot Oxon OX11 OQX, UK

${ }^{d}$ Department of Chemistry, Liverpool University, Liverpool, L69 7ZD, UK $\dagger$ Electronic supplementary information (ESI) available. See DOI: 10.1039/ c3cp50710f
}

aerobic oxidation of benzyl alcohol. ${ }^{16}$ In a typical reaction, besides benzaldehyde, toluene, benzoic acid and benzyl benzoate are also formed,

$$
2 \mathrm{PhCH}_{2} \mathrm{OH} \rightarrow \mathrm{PhCHO}+\mathrm{PhCH}_{3}+\mathrm{H}_{2} \mathrm{O}
$$

lowering the selectivity of benzaldehyde. Among the by-products detected, toluene is formed in substantial amount and hence it was necessary to understand the mechanism of its formation. Toluene has been reported to be formed by the disproportionation of benzyl alcohol [eqn (I)]. ${ }^{17,18}$

$$
\mathrm{PhCH}_{2} \mathrm{OH} \stackrel{\mathrm{O}_{2}}{\rightarrow} \mathrm{PhCHO}+\mathrm{H}_{2} \mathrm{O}
$$

Benzaldehyde is formed by the oxidative dehydrogenation of benzyl alcohol [eqn (II)] and further oxidation of benzaldehyde results in benzoic acid. Previous kinetics studies, on the mechanism of these two reactions, have revealed that the adsorbed state for the disproportionation reaction is different from that of the oxidative dehydrogenation. ${ }^{18}$ In situ spectroscopic methods are the best tools to characterize these adsorbed species over the catalyst surface. ${ }^{19-21}$ However, for the current system, this could not be done earlier because benzaldehyde is formed by both disproportionation and oxidative dehydrogenation. It is difficult to distinguish between these two sources of benzaldehyde. Recently, we reported a method to quantitatively differentiate (a) oxidative dehydrogenation and (b) disproportionation reactions when both reactions are active in the same pot. ${ }^{22}$ As a part of the study, we found that gold-palladium nanoparticles 


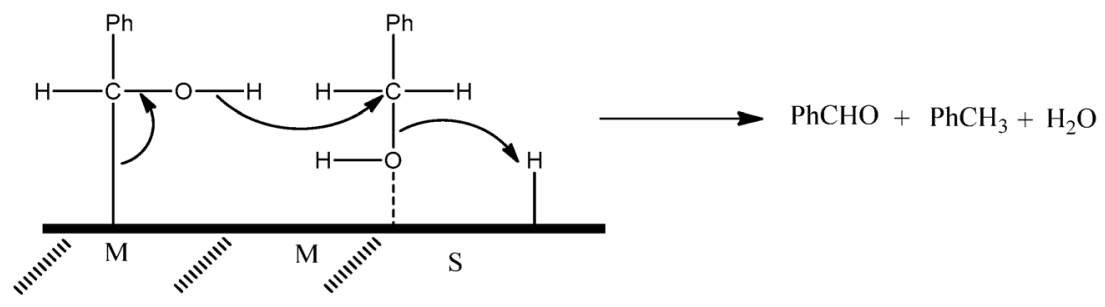

Mechanism 1

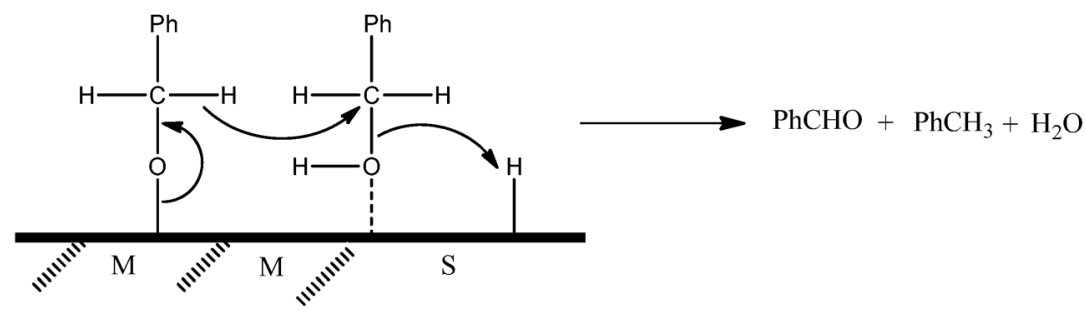

Mechanism 2

Scheme 1 Two modes of dissociative chemisorption of benzyl alcohol on the metal surface: proposed mechanisms for disproportionation of benzyl alcohol to form equimolar toluene and benzaldehyde.

supported on basic oxides, like $\mathrm{ZnO}$ and $\mathrm{MgO}$, switch-off the disproportionation completely. ${ }^{22}$ The extent of the oxidation reaction does not change with the change in support and hence, the active site for the oxidation reaction appears to be the metallic sites. However, the extent of the disproportionation is highly dependent on the support and the active site for the disproportionation reaction seems to be the metal-support interface. ${ }^{22}$ Possible molecular mechanisms for the disproportionation process were proposed (Scheme 1), key features of which were the modes of interaction of benzyl alcohol molecules with the catalyst/support surfaces (chemisorption on the metal through $\mathrm{C}-\mathrm{H}$ or $\mathrm{O}-\mathrm{H}$ bond cleavage; binding to the support involving hydrogen bonding) and the concerted nature of the bonding changes during reaction. ${ }^{18}$ For oxidative dehydrogenation, analogous mechanisms can be drawn to show the reaction of bound oxygen species with benzyl alcohol attached to the metal surface either through its benzylic $\mathrm{C}$ or $\mathrm{O}$ atom. ${ }^{18}$

These recent developments have helped us to design experiments, not possible before, where we could perform these two reactions separately, without interference from the other reaction. For example, oxidative dehydrogenation of benzyl alcohol could be performed exclusively by using $\mathrm{ZnO}$ or $\mathrm{MgO}$ supported goldpalladium catalysts under an oxygen atmosphere. Disproportionation of benzyl alcohol could be performed exclusively using $\mathrm{TiO}_{2}$ or C supported gold-palladium catalysts under anaerobic conditions. When $\mathrm{TiO}_{2}$ or C supported catalysts are used under oxygen atmosphere, benzyl alcohol undergoes oxidative dehydrogenation and disproportionation in parallel.

In situ Attenuated Total Reflection Infra-Red (ATR-IR) spectroscopy has received considerable attention as a tool for process monitoring under reaction conditions. ${ }^{23-25}$ The composition of a reaction mixture is probed by an internal reflection element (ATR sentinel). Molecules in the proximity of the sentinel's surface interact with the evanescent IR wave ranging a few $\mu \mathrm{m}$ into the probed medium resulting in molecule specific IR absorption. Implementing an IR sentinel in the bottom of an autoclave batch reactor allows for measuring in situ under conditions of up to a temperature of $350{ }^{\circ} \mathrm{C}$ and 200 bar pressure. Diffuse Reflectance Infrared Fourier Transform (DRIFT) spectroscopy is a widely available and well-understood technique for in situ studies of heterogeneous catalysts. ${ }^{26-29}$ This technique has been widely used to characterize the chemical species adsorbed on the catalyst surface and can be used as a complimentary technique to the ATR-IR method. Inelastic Neutron Scattering (INS) Spectroscopy is a complementary form of vibrational spectroscopy, where the scattering event is between a neutron and the atomic nucleus, thus the electronic nature of the material - metal, semiconductor, or insulator - is irrelevant. ${ }^{30-32}$ The scattering intensity depends on the incoherent inelastic scattering cross section and the amplitude of vibration. For ${ }^{1} \mathrm{H}$ both of these are large but they are small for all other elements present in this work; consequently the scattered intensity is dominated by hydrogen motion. We have carried out in situ spectroscopic studies over supported goldpalladium catalysts using these three techniques and in this paper we report our findings. Though many attempts have been made to study the mechanism of the benzyl alcohol oxidative dehydrogenation, no attempt has been made to study this disproportionation reaction. To the best of our knowledge, the unique combination of in situ ATR-IR, in situ DRIFT and INS techniques has never been attempted before.

\section{Experimental}

\section{Materials}

Benzyl alcohol (Aldrich, anhydrous $>99 \%$ ), $\mathrm{TiO}_{2}$ (P25 Evonik), ZnO (Sigma Aldrich), MgO (BDH), Activated C (Darco@ G60, 
Sigma Aldrich), $\mathrm{HAuCl}_{4}$ (Sigma Aldrich) and $\mathrm{PdCl}_{2}$ (Johnson Matthey) were used without further purification. Supported gold-palladium catalysts were prepared by a sol immobilization method and the detailed procedure for preparing these catalysts is reported elsewhere. ${ }^{18,22}$ These catalysts were used without any further modifications.

\section{In situ ATR-IR spectroscopy}

In situ ATR-IR monitoring of the reactions was conducted in a $40 \mathrm{~mL}$ Parr stainless steel autoclave reactor equipped with a Mettler Toledo ReactIR 45m ATR-IR instrument using a diamond sentinel and a $\mathrm{HgCdTe}$ detector at $-196{ }^{\circ} \mathrm{C}$ in the spectral range of $4000-650 \mathrm{~cm}^{-1} \cdot 33,34$ The reaction temperature was monitored and maintained using a thermocouple fitted into the reactor and connected to the controller. The reaction mixture was stirred at $1100 \mathrm{rpm}$ to avoid any mass transfer limitations. The reactor vessel was charged with $15 \mathrm{~mL}$ of benzyl alcohol and $0.015 \mathrm{~g}$ of catalyst, then was closed and purged with either pure $\mathrm{O}_{2}$ or Ar thrice with constant stirring and finally pressurized to 5 bar and 20 bar, respectively. This pressure was maintained throughout the reaction time with constant replenishment in the case of $\mathrm{O}_{2}$. Heating of the reactor was started with constant stirring and ATR-IR spectra of the reaction mixture were measured every $60 \mathrm{~s}$ at a resolution of $4 \mathrm{~cm}^{-1}$. However, for clarity, only selected spectra are presented here. Difference spectra were created by subtraction of a pure benzyl alcohol reference spectrum acquired at $120{ }^{\circ} \mathrm{C}$ under 20 bar Ar pressure from the in situ reaction spectrum in liquid phase. Time on-line profiles to follow benzyl alcohol consumption and benzaldehyde production at $120{ }^{\circ} \mathrm{C}$ were constructed by integration of the 1016 and $1039 \mathrm{~cm}^{-1}$ double band (integration limits $1060-950 \mathrm{~cm}^{-1}$, baseline $1070-930 \mathrm{~cm}^{-1}$ ) and the $\nu(\mathrm{C}=\mathrm{O})$ band at $1703 \mathrm{~cm}^{-1}$ (integration limits 1730$1670 \mathrm{~cm}^{-1}$, baseline $\left.1740-1660 \mathrm{~cm}^{-1}\right)$, respectively. The species present in the liquid phase (mostly) are characterized by this technique. For ATR-IR studies, we have used 1\%AuPd/MgO catalyst whereas for other studies we have used 1\%AuPd/ZnO catalyst. Our earlier studies have shown that, mechanistically these two catalysts behave in a similar way and thus could be swapped for the mechanistic investigation.

\section{DRIFT spectroscopy}

DRIFT spectroscopy studies were performed using a Bruker Tensor 27 spectrometer fitted with a HgCdTe (MCT) detector and a Harrick Praying Mantis HVC-DRP-4 cell equipped with ZnSe windows. Samples were mixed with benzyl alcohol and added to the cell. An alternative method of adding benzyl alcohol was the use of an in-line saturator heated to $150{ }^{\circ} \mathrm{C}$. After an initial scan at room temperature the sample was heated to $280{ }^{\circ} \mathrm{C}$ at $1{ }^{\circ} \mathrm{C} \mathrm{min}^{-1}$ under an atmosphere of flowing $\mathrm{N}_{2} 20 \mathrm{ml} \min ^{-1}$ or $\mathrm{O}_{2} 20 \mathrm{ml} \min ^{-1}$ (flows regulated by Bronkhorst mass flow meters). Spectra were run in the range of $4000-600 \mathrm{~cm}^{-1}$, with 64 accumulation scans, every $10{ }^{\circ} \mathrm{C}$. Difference spectra were used with catalysts prior to the addition of benzyl alcohol being used as the background. This removed interference from bands associated with PVA used as a stabilizing agent in catalyst preparation. Therefore, all the spectra observed were from that of adsorbed species on the catalyst surface.

\section{Inelastic neutron scattering (INS) spectroscopy}

INS spectra were recorded with the MAPS spectrometer at ISIS; the instrument is described in detail elsewhere. ${ }^{32}$ In brief, a single energy, $E_{\mathrm{i}}$, is selected from the incident, pulsed polychromatic beam by a Fermi chopper; after scattering from the sample, the scattered neutrons are detected by a large area $\left(\sim 16 \mathrm{~m}^{2}\right)$ of ${ }^{3} \mathrm{He}$ detectors. For these measurements MAPS was run with the high resolution slit package $\left(\sim 1.5 \% E_{\mathrm{i}}\right)$ in the Fermi chopper. Incident energies of $4033 \mathrm{~cm}^{-1}(600 \mathrm{meV})$, $2017 \mathrm{~cm}^{-1}(250 \mathrm{meV})$ and $484 \mathrm{~cm}^{-1}(60 \mathrm{meV})$ were used to record the $\mathrm{O}-\mathrm{H} / \mathrm{C}-\mathrm{H}$ stretch region, the fingerprint region and the region where framework motions (torsions, $\mathrm{C}-\mathrm{C}-\mathrm{C}$ bend) occur. The catalyst $(8 \mathrm{~g})$ was placed inside Conflat sealed, flow through Inconel cans between quartz wool. ${ }^{35}$ Then the inlet line of the can was connected with gas ( $\mathrm{He}$ ) and left for period of $12 \mathrm{~h}$ at a temperature of $120{ }^{\circ} \mathrm{C}$ to remove any absorbed species. Benzyl alcohol vapour was dosed onto the surface of the catalyst at room temperature $\left(25^{\circ} \mathrm{C}\right)$ for a period of $12 \mathrm{~h}$. The system for dosing benzyl alcohol consists of a He line going through a heated benzyl alcohol $\left(150{ }^{\circ} \mathrm{C}\right)$ reservoir and MAPS sample cell kept at $25{ }^{\circ} \mathrm{C}$. The cans were then loaded into a closed cycle refrigerator in MAPS, cooled to $<-253{ }^{\circ} \mathrm{C}$ and the spectra recorded for 6-8 $\mathrm{h}$ at each of the three incident energies. All species chemisorbed species or strongly adsorbed on to the solid catalyst surface are characterized by this technique.

\section{Results and discussion}

\section{In situ ATR-IR spectroscopy}

The transformations of benzyl alcohol over $1 \% \mathrm{AuPd} / \mathrm{TiO}_{2}$, $1 \% \mathrm{AuPd} / \mathrm{MgO}$ and $1 \% \mathrm{AuPd} / \mathrm{C}$ catalysts were monitored using in situ ATR-IR reactor under both aerobic and anaerobic conditions to study (a) disproportionation (b) oxidative dehydrogenation reactions. In situ ATR-IR spectroscopic investigation, using the ATR-IR probe fitted in a stirred autoclave reactor, yields mostly information about the liquid phase composition and intermediates during the course of the reaction. ${ }^{33,34}$ Fig. 1 displays the absorbance (difference) spectra, with respect to pure benzyl alcohol $\left(120^{\circ} \mathrm{C}, 20 \mathrm{bar}\right.$ Ar), during the course of the reaction using $1 \% \mathrm{AuPd} / \mathrm{TiO}_{2}, 1 \% \mathrm{AuPd} / \mathrm{MgO}$ and $1 \% \mathrm{AuPd} / \mathrm{C}$ catalysts under both anaerobic $\left(120{ }^{\circ} \mathrm{C}, 20 \mathrm{bar} \mathrm{Ar}\right)$ and aerobic $\left(120{ }^{\circ} \mathrm{C}, 5\right.$ bar $\left.\mathrm{O}_{2}\right)$ conditions. Positive band(s) in the spectra indicate an increase in the concentration of the component(s) corresponding to the band and negative band(s) indicate a decrease in concentration of the component(s) corresponding to the band. All spectra show characteristic bands assignable to benzyl alcohol (substrate), benzaldehyde and water (products). Vibrational bands corresponding to toluene are largely masked by both benzyl alcohol and benzaldehyde bands and hence it was not possible to observe toluene using this in situ ATR-IR spectroscopic method. ${ }^{23,24}$ However, GC and GC-MS studies of the reaction mixtures, reported earlier, clearly indicate the 


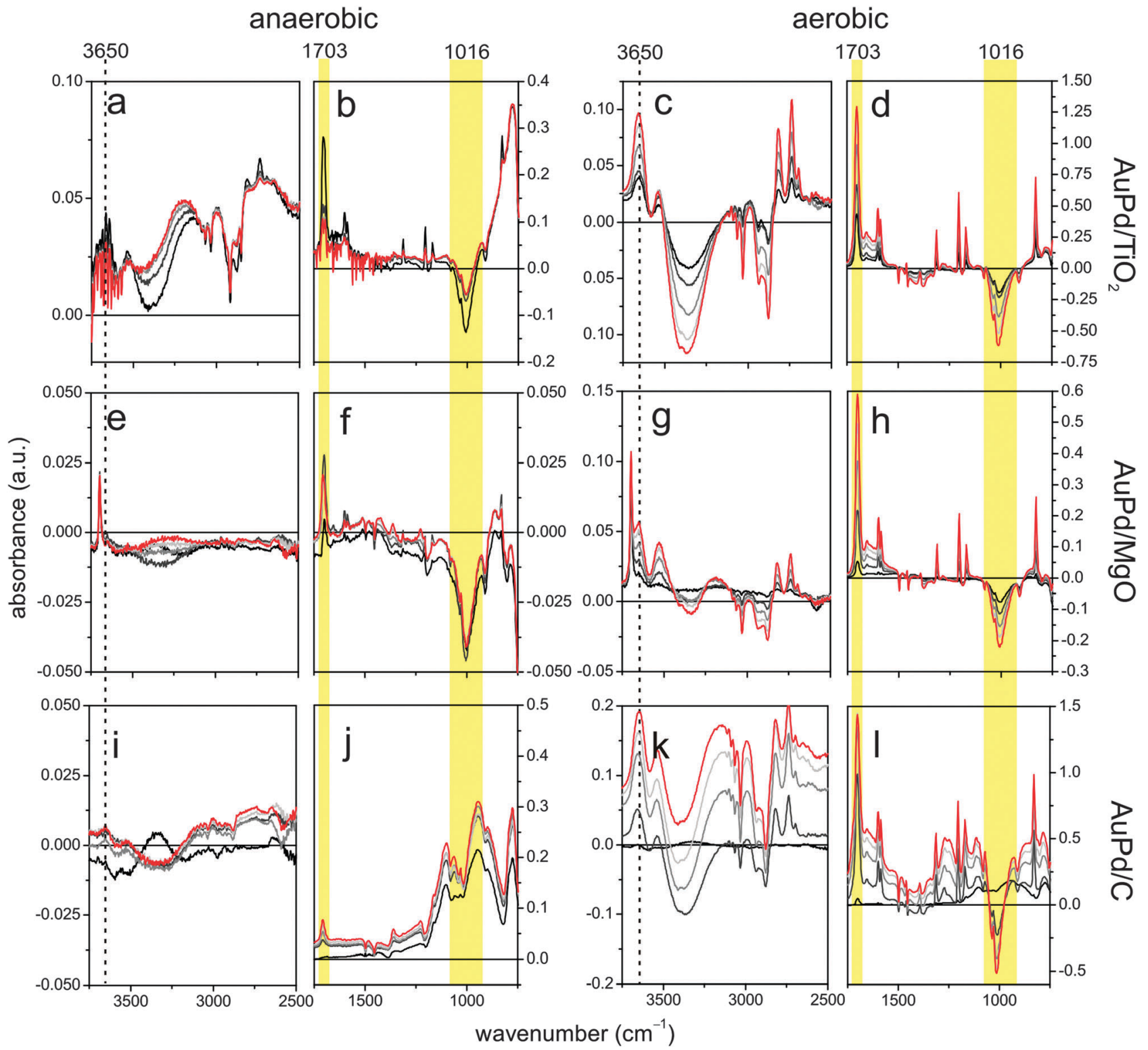

Fig. 1 In situ ATR-IR difference spectra for the reaction of benzyl alcohol using $1 \% \mathrm{AuPd} / \mathrm{TiO}_{2}, 1 \% \mathrm{AuPd} / \mathrm{MgO}$ and $1 \% \mathrm{AuPd} / \mathrm{C}$ catalysts under anaerobic and aerobic conditions in a stirred autoclave reactor. Only $3750-2500 \mathrm{~cm}^{-1}\left[\nu(\mathrm{O}-\mathrm{H})\right.$ and $\nu(\mathrm{C}-\mathrm{H})$ regions] and $1750-750 \mathrm{~cm}^{-1}$ [fingerprint region] are presented here for clarity. Pure benzyl alcohol spectrum at $20 \mathrm{bar} A r, 120^{\circ} \mathrm{C}$ was used as reference spectrum to calculate the difference spectra. Displayed spectra taken at $120{ }^{\circ} \mathrm{C}$ for $t=0^{\prime}$ (black), 30' (dark grey), 60' (grey), 90' (light grey), 120' (red). (a and b) 1\%AuPd/TiO 2 , anaerobic; (c and d) 1\%AuPd/TiO 2 , aerobic; (e and f) 1\%AuPd/MgO, anaerobic; ( $g$ and h) AuPd/MgO, aerobic; ( $\mathrm{i}$ and j) $1 \%$ AuPd/C, anaerobic and ( $\mathrm{k}$ and I), aerobic. The bands $\left(1703 \mathrm{~cm}^{-1}\right.$ for benzaldehyde and $1016 \mathrm{~cm}{ }^{-1}$ for benzyl alcohol) used for integration for the time on-line concentration profile (Fig. 2) are highlighted.

formation of toluene. ${ }^{18,36,37}$ In this article the discussion is limited to non-overlapping bands and their corresponding components such as benzyl alcohol and benzaldehyde only. For $1 \% \mathrm{AuPd} / \mathrm{TiO}_{2}$, under anaerobic conditions, disproportionation of benzyl alcohol is partially observed because of the bands around $1703 \mathrm{~cm}^{-1}$, corresponding to benzaldehyde (Fig. 1a and b). As mentioned above toluene could not be observed by any characteristic bands. Two specific bands, $1016 \mathrm{~cm}^{-1} / 1039 \mathrm{~cm}^{-1}$ bands of benzyl alcohol and $1703 \mathrm{~cm}^{-1}$ band of benzaldehyde were chosen and their areas under the band, for different time intervals, were integrated and presented in Fig. 2. It is important to note that the time in the $x$-axis starts when the reaction temperature reaches $120{ }^{\circ} \mathrm{C}$. For the $1 \% \mathrm{AuPd} / \mathrm{TiO}_{2}$ catalyst, under anaerobic conditions, the area corresponding to benzaldehyde increases initially slightly and very slowly decreases with time; for the same time period there is a slight increase in the area of the band corresponding to benzyl alcohol. This observation is different from what has been seen by GC analysis for the disproportionation reaction under similar reaction conditions, where we found that there is a steady increase in the amounts of benzaldehyde and toluene at the expense of benzyl alcohol. This difference could be 


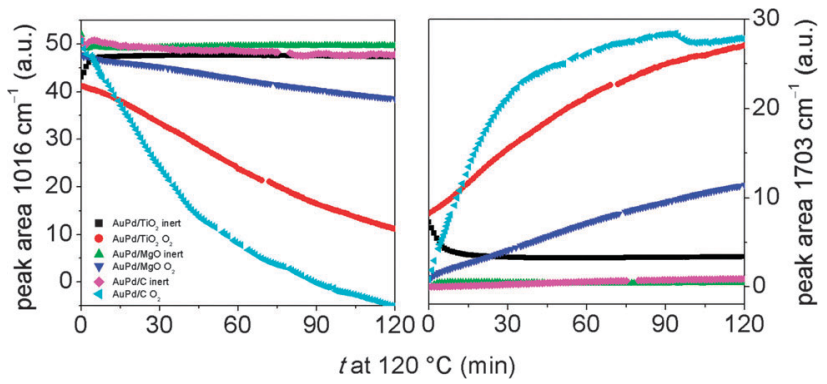

Fig. 2 ATR-IR time on line peak area profiles of benzyl alcohol (left) and benzaldehyde (right) obtained by integrating the peak area of bands at $1016 \mathrm{~cm}^{-1}$ (benzyl alcohol) and $1703 \mathrm{~cm}^{-1}(\nu(\mathrm{C}=\mathrm{O})$ of benzaldehyde) from Fig. 1. Key: black squares: $1 \% \mathrm{AuPd} / \mathrm{TiO}_{2}$, anaerobic; red circles: $1 \% \mathrm{AuPd} / \mathrm{TiO}_{2}$ aerobic; green triangles: $1 \% \mathrm{AuPd} / \mathrm{MgO}$, anaerobic; blue triangles: $1 \% \mathrm{AuPd} /$ $\mathrm{MgO}$, aerobic; magenta diamond: $1 \% \mathrm{AuPd} / \mathrm{C}$ anaerobic and cyan triangles: $1 \%$ AuPd/C aerobic.

attributed to the formation of either hemiacetal or acetal from benzaldehyde and benzyl alcohol over gold-palladium supported on an acidic support like $\mathrm{TiO}_{2}$, however, their presence in the reaction mixture could not be verified by either GC or GCMS. ${ }^{22,36}$ The consumption of benzaldehyde by decarbonylation to form benzene could not be ruled out; the strong absorption expected for $\mathrm{CO}$ could not be detected by the current instrument because of the strong absorption of the diamond sentinel in the characteristic $\mathrm{CO}$ stretching vibration region $\left(1850-2150 \mathrm{~cm}^{-1}\right)$. For the same catalyst, under aerobic conditions, (Fig. $1 \mathrm{c}$ and d), a substantial increase of the $\nu(\mathrm{C}=\mathrm{O})$ band of benzaldehyde at $1703 \mathrm{~cm}^{-1}$ and another band at $828 \mathrm{~cm}^{-1}$ was observed. Furthermore, $\mathrm{C}-\mathrm{H}$ stretching vibrations of the aldehyde group located at 2818, 2736, $2697 \mathrm{~cm}^{-1}$ gain in intensity. Corresponding decrease in the area of benzyl alcohol $\left(1016 \mathrm{~cm}^{-1}\right.$ and $1039 \mathrm{~cm}^{-1}$ ) was also observed (Fig. 2). Water formation results in increase of a band at $3650 \mathrm{~cm}^{-1}$. The rate of increase in benzaldehyde band or decrease in the benzyl alcohol band, under aerobic condition, is substantially higher than that under anaerobic conditions. From previous studies it has been proven that under anaerobic conditions, the only pathway for benzyl alcohol consumption and benzaldehyde formation is disproportionation whereas under anaerobic conditions, benzaldehyde is formed by both disproportionation and oxidative dehydrogenation. However, with the present set of data, we could not distinguish between these two pathways. For AuPd/MgO supported catalyst, a remarkable feature at $3697 \mathrm{~cm}^{-1}$ showed up under both anaerobic and aerobic conditions (Fig. 1e and g). This is the $\nu\left(\mathrm{OH}_{\mathrm{MgO}}\right)$ band from the catalyst support. This assignment of the hydroxyl band is confirmed by the FT-IR measurement of the fresh 1\%AuPd/ $\mathrm{MgO}$ catalyst that has a sharp band exactly at $3700 \mathrm{~cm}^{-1}$ (Fig. S1, ESI $\dagger$ ). However, no other bands attributable to species adsorbed on the $\mathrm{MgO}$ support could be assigned. Under anaerobic conditions, there is no increase in the formation of the benzaldehyde after a few minutes of the start of the reaction. This initial formation has been attributed to the oxidative dehydrogenation because of the adsorbed oxygen on the catalyst surface which has been proven earlier in a study using a micro packed bed reactor. This further substantiates the fact that benzyl alcohol does not undergo any transformation over $1 \% \mathrm{AuPd} / \mathrm{MgO}$ catalyst in the absence of atmospheric oxygen. However, under aerobic condition, there is a steady increase in benzaldehyde concentration and a corresponding decrease in the benzyl alcohol concentration, but at a much lower rate compared to $1 \% \mathrm{AuPd} / \mathrm{TiO}_{2}$. This is because the only reaction that is active under these conditions is oxidative dehydrogenation whereas in the case of $1 \% \mathrm{AuPd} / \mathrm{TiO}_{2}$ both oxidative dehydrogenation and disproportionation reactions are active. Finally, reactions of benzyl alcohol, over 1\%AuPd/C catalyst, were studied under aerobic and anaerobic conditions and results are presented in Fig. 1 (i, j for anaerobic condition, $\mathrm{k}, \mathrm{l}$ for aerobic conditions). Under anaerobic conditions, in contrast to $1 \% \mathrm{AuPd} / \mathrm{TiO}_{2}$, there is a steady increase in the concentration of benzaldehyde with a corresponding decrease in the benzyl alcohol concentration. This is in line with the GC observation that benzyl alcohol undergoes disproportionation under these conditions. ${ }^{37}$ Under aerobic conditions, using the same catalyst, benzaldehyde is formed at a much higher rate (Fig. 2). From these in situ ATR-IR spectroscopic studies, the rate of formation of benzaldehyde obeys the following trend; $1 \% \mathrm{AuPd} / \mathrm{C}($ aerobic $)>1 \% \mathrm{AuPd} / \mathrm{TiO}_{2}$ (aerobic) $>1 \% \mathrm{AuPd} / \mathrm{MgO}$ $($ aerobic $)>1 \% \mathrm{AuPd} / \mathrm{C}($ anaerobic $)>1 \% \mathrm{AuPd} / \mathrm{TiO}_{2}($ anaerobic $)=$ $1 \% \mathrm{AuPd} / \mathrm{MgO}$ (anaerobic). Except the $1 \% \mathrm{AuPd} / \mathrm{TiO}_{2}$ (anaerobic) reaction, this trend follows the GC based activity trend. ${ }^{37}$

\section{DRIFT spectroscopy}

In order to investigate the surface species, that can cast light on the reaction mechanism, DRIFT spectroscopic studies were performed on $1 \% \mathrm{AuPd} / \mathrm{TiO}_{2}$ and $1 \% \mathrm{AuPd} / \mathrm{ZnO}$ catalysts dosed with small quantities of benzyl alcohol. All standards and bands observed are shown in Table 1 with spectra shown in the ESI $\dagger$ (S2). Initial room temperature spectra collected from experiments performed under an inert atmosphere, for both catalysts, showed bands associated with benzyl alcohol and also a carbonyl band centred at $1702 \mathrm{~cm}^{-1}$, which is indicative of benzaldehyde. The presence of benzaldehyde was also noted at the start of the reaction in the ATR-IR experiments under anaerobic conditions. As previously stated, no disproportionation

Table 1 Vibrational modes assignment in the $1800-1300 \mathrm{~cm}^{-1}$ region at $22^{\circ} \mathrm{C}$

\begin{tabular}{|c|c|c|c|c|c|c|}
\hline $\begin{array}{l}\text { Benzyl } \\
\text { alcohol } \\
\text { (neat) }\end{array}$ & $\begin{array}{l}\text { Benzalde- } \\
\text { hyde } \\
\text { (neat) }\end{array}$ & $\begin{array}{l}\text { Toluene } \\
\text { (neat) }\end{array}$ & $\begin{array}{l}\text { Benzoic } \\
\text { acid } \\
\text { (neat) }\end{array}$ & $\begin{array}{l}1 \mathrm{wt} \% \\
\mathrm{AuPd} / \\
\mathrm{TiO}_{2} \mathrm{~N}_{2} \\
\text { flow }\end{array}$ & $\begin{array}{l}1 \mathrm{wt} \% \\
\mathrm{AuPd} / \\
\mathrm{ZnO} \mathrm{N}_{2} \\
\text { flow }\end{array}$ & Assignment \\
\hline & 1700 & & 1685 & $\begin{array}{l}1702 \\
1654\end{array}$ & 1702 & $\begin{array}{l}\nu(\mathrm{C}=\mathrm{O}) \\
\nu(\mathrm{C}=\mathrm{O})\end{array}$ \\
\hline 1607 & 1599 & 1604 & 1603 & 1598 & 1598 & $\nu(\mathrm{C}=\mathrm{C})+\delta(\mathrm{C}-\mathrm{H})$ \\
\hline 1586 & 1584 & & 1584 & 1584 & 1584 & $\nu(\mathrm{C}=\mathrm{C})+\delta(\mathrm{C}-\mathrm{H})$ \\
\hline 1496 & & 1495 & 1497 & 1496 & 1496 & $\delta(\mathrm{C}-\mathrm{H})+\nu(\mathrm{C}=\mathrm{C})$ \\
\hline 1454 & $\begin{array}{l}1454 \\
1424\end{array}$ & 1458 & $\begin{array}{l}1454 \\
1424\end{array}$ & 1454 & $\begin{array}{l}1454 \\
1418\end{array}$ & $\delta(\mathrm{C}-\mathrm{H})+\nu(\mathrm{C}=\mathrm{C})$ \\
\hline 1369 & & 1379 & & $\begin{array}{l}1391 \\
1369\end{array}$ & $\begin{array}{l}1370 \\
1340\end{array}$ & $\begin{array}{l}\delta(\mathrm{O}-\mathrm{H}) \\
\delta(\mathrm{C}-\mathrm{H})+\nu(\mathrm{C}=\mathrm{C})\end{array}$ \\
\hline & 1326 & & 1325 & & & \\
\hline
\end{tabular}

1311 
reaction occurs on basic $1 \% \mathrm{AuPd} / \mathrm{ZnO}$ catalysts, but residual surface absorbed oxygen species on the catalyst surface result in some oxidation of benzyl alcohol at the start of the reaction. As observed in the ATR studies and previous studies in batch reactors, total removal of oxygen is difficult and limited oxidation occurs at the start of reactions. It is important to note, however, that total removal of oxygen from the $1 \% \mathrm{AuPd} / \mathrm{ZnO}$ catalyst surface within a micro reactor set-up has previously shown that no benzyl alcohol oxidation occurs under anaerobic conditions. $^{36}$ As oxygen was present even when using inert gas flows in the cell, no important information could be elucidated from changing from inert to oxygen-containing atmospheres (spectra from experiments performed under oxygen containing atmospheres are shown in the ESI $\dagger$ (Fig. S2)).

Heating of the benzyl alcohol dosed catalysts under a flow of inert gas resulted in desorption of the benzaldehyde and benzyl alcohol by $180{ }^{\circ} \mathrm{C}$. It is important to note the presence of bands associated with irreversibly adsorbed species for both $1 \% \mathrm{AuPd} /$ $\mathrm{TiO}_{2}$ and $1 \% \mathrm{AuPd} / \mathrm{ZnO}$ catalyst after heating samples to $280{ }^{\circ} \mathrm{C}$ (Fig. 3). For both catalysts, bands associated with aromatic $\mathrm{C}=\mathrm{C}$ and $\mathrm{C}-\mathrm{H}$ modes (1592-1595 $\mathrm{cm}^{-1}$ and 1493-1496 $\mathrm{cm}^{-1}$ ) were observed. The $1 \% \mathrm{AuPd} / \mathrm{ZnO}$ catalyst had strong bands at (1533, 1419 and $1374 \mathrm{~cm}^{-1}$ ), indicative of benzoate species previously observed in in situ ATR infra-red studies of benzyl alcohol using $\mathrm{Pt} / \mathrm{Al}_{2} \mathrm{O}_{3}$ catalysts. ${ }^{23}$ Bands associated with benzoate were also observed on $1 \% \mathrm{AuPd} / \mathrm{TiO}_{2}$, though these were considerably less intense than that observed on the $\mathrm{ZnO}$ catalyst. However, in addition to benzoate, a band at $1654 \mathrm{~cm}^{-1}$ with a shoulder at $1670 \mathrm{~cm}^{-1}$ was present on the $1 \% \mathrm{AuPd} / \mathrm{TiO}_{2}$ catalyst. The band at $1670 \mathrm{~cm}^{-1}$ is indicative of carbonyl bands associated with a conjugated carboxylic acid group and matches that observed for benzoic acid. ${ }^{23}$ The lower frequency $1654 \mathrm{~cm}^{-1}$ is at the low frequency extreme of the range observed for carbonyl bands and demonstrates significant

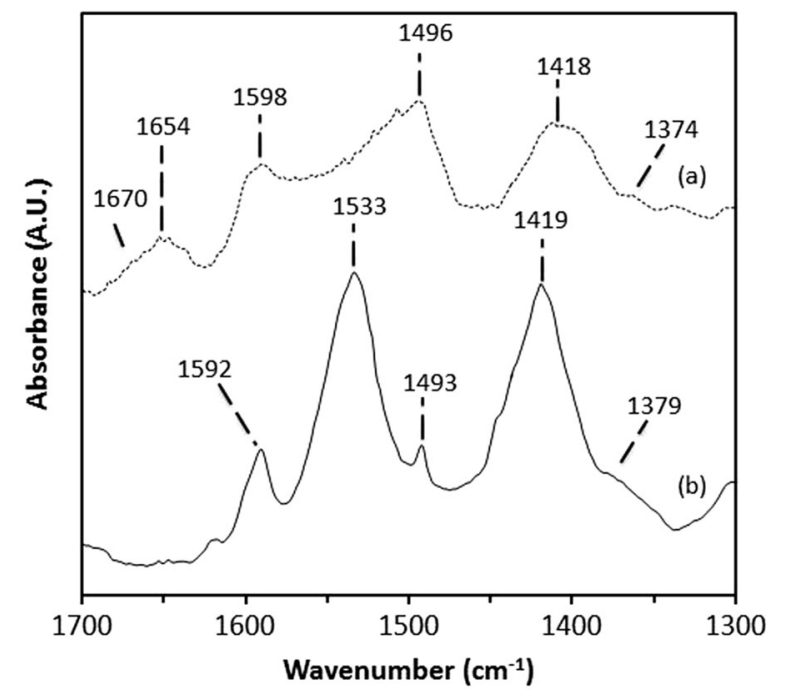

Fig. 3 DRIFT spectra of benzyl alcohol dosed catalysts after heating the samples to $280{ }^{\circ} \mathrm{C}\left(1{ }^{\circ} \mathrm{C} \mathrm{min}{ }^{-1}\right)$. Key: (a) $1 \% \mathrm{AuPd} / \mathrm{TiO}_{2}$ and (b) $1 \% \mathrm{AuPd} / \mathrm{ZnO}$. Bands labelled are referred to in the text. electron donation to the group, weakening the $\mathrm{C}=\mathrm{O}$ bond. This low wavenumber carbonyl band could indicate electron donation from Au or Pd metal, showing chemisorption of the species to the metal via the carbon of the carbonyl functional group but might also arise from weak adsorption of benzaldehyde to the metal through the carbonyl O-atom $\left[c f .1667 \mathrm{~cm}^{-1}\right.$ for $\mathrm{CH}_{3} \mathrm{CHO}$ on $\left.\mathrm{Pt}(111)^{38}\right]$. However, it is noted that weak adsorption through the carbonyl O-atom is less likely for species still bound to the surface at $280{ }^{\circ} \mathrm{C}$. This ambiguity in interpretation and the fact that product species are being observed means that their structure cannot be used to infer how dissociative chemisorption of benzyl alcohol occurs on the different catalysts. The proposed interaction of the metal with the carbon of the carbonyl functional group seen in the $1 \% \mathrm{AuPd} / \mathrm{TiO}_{2}$ catalyst might suggest that benzyl alcohol was chemisorbed by cleavage of a benzylic $\mathrm{C}-\mathrm{H}$ bond and not the $\mathrm{O}-\mathrm{H}$ bond. The reverse is true if the carbonyl oxygen of the product is attached to the metal surface and this is indicative of its precursor surface species. Both modes of interaction have been previously suggested as possible surface species. ${ }^{19}$ As the $1654 \mathrm{~cm}^{-1}$ signal was observed only for the $1 \% \mathrm{AuPd} / \mathrm{TiO}_{2}$ catalyst, which facilitates the disproportionation reaction, it suggests the importance of this chemisorbed species in the disproportionation reaction. This is re-enforced by the total absence of the $1655 \mathrm{~cm}^{-1}$ band in the basic $\mathrm{ZnO}$ supported catalyst which does not bring about disproportionation.

\section{Inelastic neutron scattering spectroscopy}

Fig. 4 and 5 show the adsorption and reaction of benzyl alcohol on $1 \% \mathrm{AuPd} / \mathrm{TiO}_{2}$ and $1 \% \mathrm{AuPd} / \mathrm{ZnO}$ catalyst in the $\mathrm{C}-\mathrm{H}$ stretch region and Fig. 6 and 7 the corresponding spectra in the fingerprint region. Reference spectra of pure benzyl alcohol, benzaldehyde and toluene in the same regions are shown in

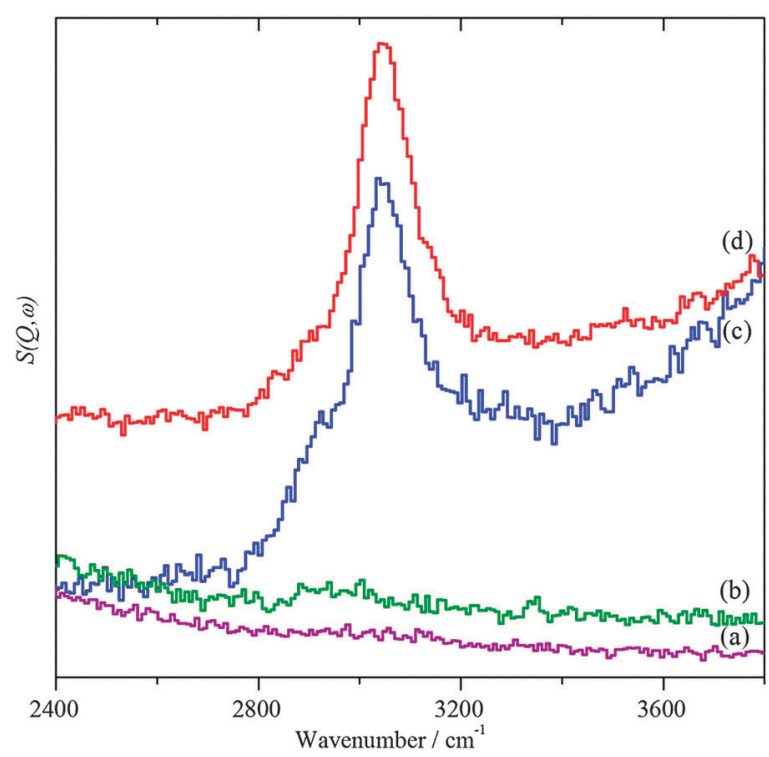

Fig. 4 INS spectra in the $\mathrm{C}-\mathrm{H}$ stretch region. (a) Bare $\mathrm{TiO}_{2}$ support after dosing with benzyl alcohol, (b) AuPd/TiO 2 catalyst after $20 \mathrm{~h}$ helium purge at $150{ }^{\circ} \mathrm{C}$, (c) after dosing with benzyl alcohol and (d) after heating in flowing helium at $150^{\circ} \mathrm{C}$. 


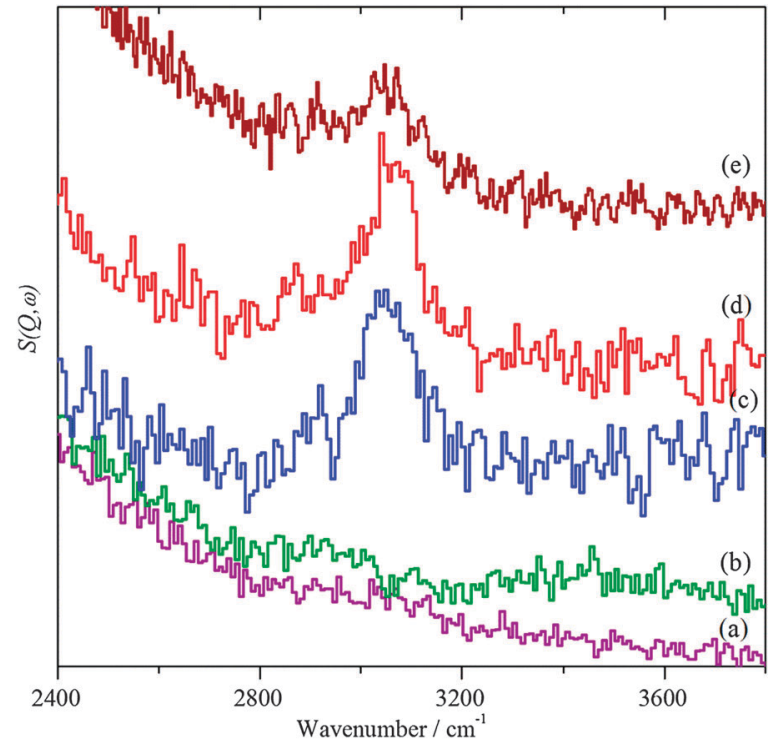

Fig. 5 INS spectra in the $\mathrm{C}-\mathrm{H}$ stretch region. (a) Bare $\mathrm{ZnO}$ support after dosing with benzyl alcohol, (b) AuPd/ZnO catalyst after helium purge at $150^{\circ} \mathrm{C}$, (c) after dosing with benzyl alcohol, (d) after heating in flowing helium at $150^{\circ} \mathrm{C}$ and (e) after reaction with $\mathrm{O}_{2}$.

the ESI $\dagger$ (Fig. S3 and S4). It can be seen that for both supports under the conditions used here, there is no adsorption of benzyl alcohol on the bare support, Fig. 4a, 5a, 6a, and 7a; the observed features are all assigned to species on the AuPd nanoparticles. The generally weak intensities observed are consistent with the low metal loading employed.

From infrared and Raman spectra of solid benzyl alcohol, ${ }^{39}$ the out-of-plane C-O-H bending modes are assigned at $695 \mathrm{~cm}^{-1}$, the $\mathrm{CH}_{2}$ scissors mode at $1435 \mathrm{~cm}^{-1}$, the methylene $\mathrm{C}-\mathrm{H}$

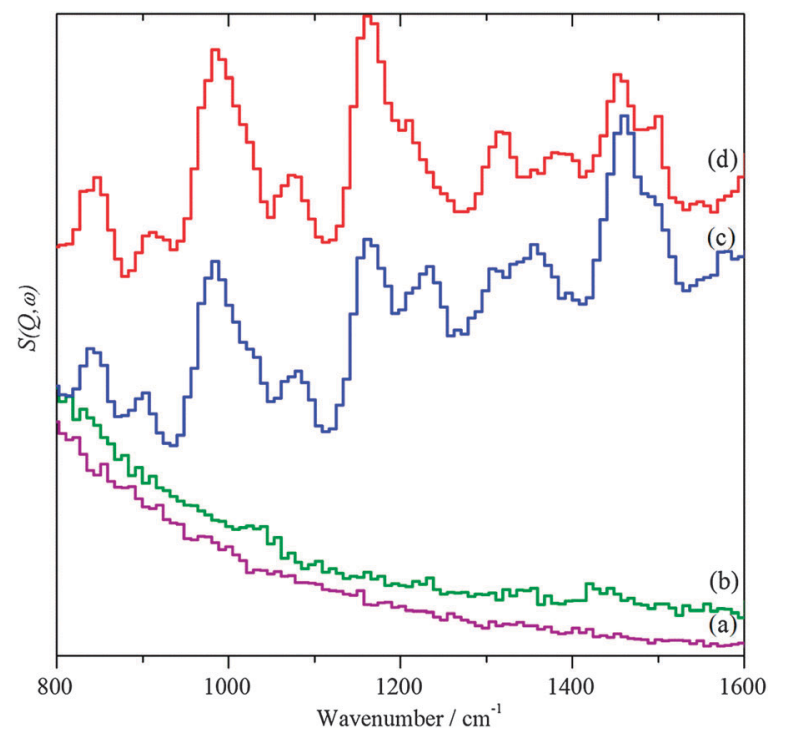

Fig. 6 INS spectra in the fingerprint region. (a) Bare $\mathrm{TiO}_{2}$ support after dosing with benzyl alcohol, (b) AuPd/TiO ${ }_{2}$ catalyst after $20 \mathrm{~h}$ helium purge at $150{ }^{\circ} \mathrm{C}$, (c) after dosing with benzyl alcohol and (d) after heating in flowing helium at $150{ }^{\circ} \mathrm{C}$.

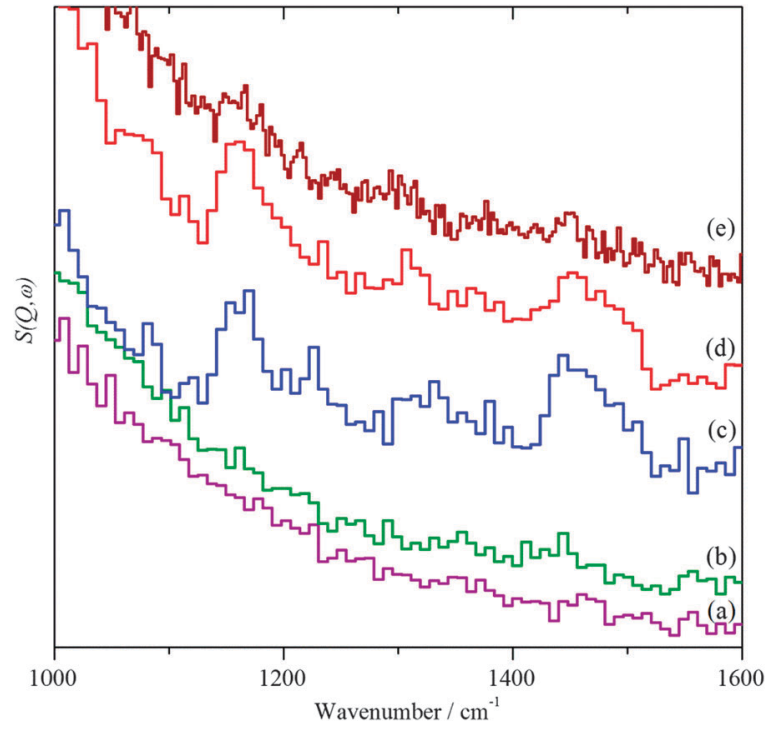

Fig. 7 INS spectra in the fingerprint region. (a) Bare $\mathrm{ZnO}$ support after dosing with benzyl alcohol, (b) $1 \%$ AuPd/ZnO catalyst after helium purge at $150{ }^{\circ} \mathrm{C}$, (c) after dosing with benzyl alcohol, (d) after heating in flowing helium at $150{ }^{\circ} \mathrm{C}$ and (e) after reaction with $\mathrm{O}_{2}$.

stretch modes at $2850-2950 \mathrm{~cm}^{-1}$, the aromatic C-H stretch modes at $3006-3090 \mathrm{~cm}^{-1}$ and the $\mathrm{O}-\mathrm{H}$ stretch at $3170 \mathrm{~cm}^{-1}$. $A b$ initio calculations of the complete unit cell ${ }^{40}$ using the CASTEP code confirm these assignments and also show that the $\mathrm{CH}_{2}$ twist is at $1233 \mathrm{~cm}^{-1}$ and the in-plane $\mathrm{C}-\mathrm{O}-\mathrm{H}$ bending modes are at 1445 and $1507 \mathrm{~cm}^{-1}$, thus overlapping the $\mathrm{CH}_{2}$ scissors modes.

Exposure of the supported catalysts to benzyl alcohol results in new features in both the $\mathrm{C}-\mathrm{H}$ stretch and fingerprint regions, Fig. $4 c, 5 c, 6 c$, and 7c. Comparison with the reference spectra, Fig. S3 and S4 (ESI $\dagger$ ), suggests that this is benzyl alcohol. Overlaying the spectra of pure benzyl alcohol and that adsorbed on $1 \% \mathrm{AuPd} / \mathrm{TiO}_{2}$, Fig. 8 , shows that the profile is unchanged apart from an additional weak, broad feature at $\sim 3210 \mathrm{~cm}^{-1}$, suggesting interaction is between the metal and the alcoholic

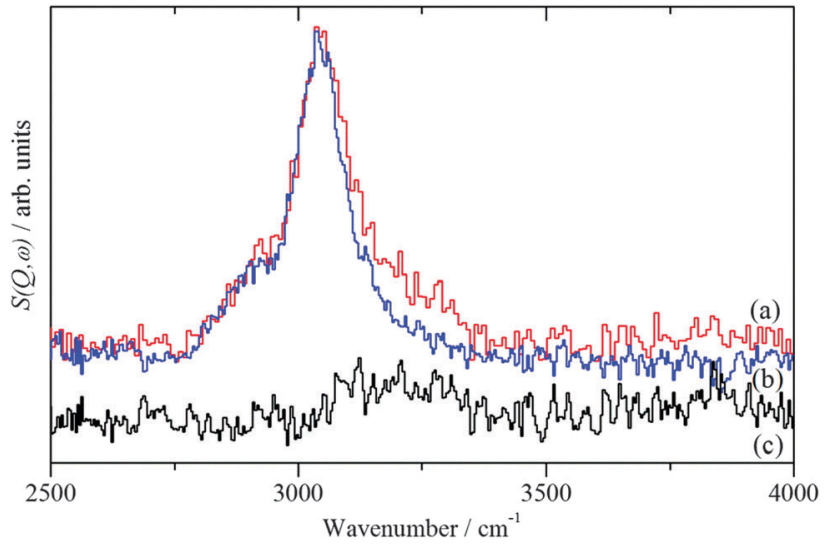

Fig. 8 Comparison of the INS spectra of (a) benzyl alcohol adsorbed on $1 \% \mathrm{AuPd} / \mathrm{TiO}_{2}$ (red trace) and (b) the pure compound (blue trace). The difference spectrum (black trace) is shown in (c) and is plotted on the same scale as (b). 
oxygen. Curve fitting the $\mathrm{C}-\mathrm{H}$ stretch region of pure benzyl alcohol, Fig. S3a (ESI $\dagger$ ), shows that the ratio of the areas of the $\mathrm{CH}_{2}$, aromatic $\mathrm{C}-\mathrm{H}$ and $\mathrm{O}-\mathrm{H}$ stretch modes is $1.9: 6.6: 1$, close to the expected ${ }^{30,32}$ ratio of $2: 5: 1$. For benzyl alcohol adsorbed on $1 \% \mathrm{AuPd} / \mathrm{TiO}_{2}$, after allowance for the $3210 \mathrm{~cm}^{-1}$ band, the ratio is: $1.6: 6: 1$, which given the modest signal-to-noise ratio, indicates that the molecule adsorbs intact, suggesting that the C-M and $\mathrm{O}-\mathbf{M}$ species in Scheme 1 are transition states rather than intermediates. There is a small shift in the $\mathrm{O}-\mathrm{H}$ stretch transition energy from 3184 down to $3172 \mathrm{~cm}^{-1}$ which would be consistent with benzyl alcohol hydrogen bonding to the neighbouring benzyl alcohol molecule. Possible assignments for the $3210 \mathrm{~cm}^{-1}$ band are to water or hydroxyls that are formed while dosing the sample at $150{ }^{\circ} \mathrm{C}$ (a temperature that is required to prevent physisorption of the benzyl alcohol on the sample). In the case of benzyl alcohol on AuPd/ZnO, the quantity of benzyl alcohol we were able to adsorb was much smaller and the signalto-noise ratio is much poorer; however, the profile matches that of pure benzyl alcohol, again indicating that the adsorption is molecular. In this case, the $3210 \mathrm{~cm}^{-1}$ band was absent.

On heating under anaerobic conditions the difference in behaviour of the two catalysts is readily apparent, in both the $\mathrm{C}-\mathrm{H}$ stretch and fingerprint regions (Fig. 4d, 5d, 6d, and 7d). For the $\mathrm{TiO}_{2}$ supported catalyst, the spectral profiles in both regions change significantly. In particular, the modes at $\sim 1230$ and $1460 \mathrm{~cm}^{-1}$, which are associated with the methylene and hydroxyl functionalities, weaken dramatically as does the signal at $2900 \mathrm{~cm}^{-1}$ assigned to the symmetric $\mathrm{CH}_{2}$ stretch; a new signal appears at $1620 \mathrm{~cm}^{-1}$. Comparison with the reference spectra shows that the changes are consistent with the loss of benzyl alcohol and formation of a mixture of toluene and benzaldehyde, although the loss of methylene signals might also be argued as suggestive of chemisorption of benzyl alcohol by benzylic $\mathrm{C}-\mathrm{H}$ cleavage as well as benzaldehyde via its carbonyl oxygen. For the $\mathrm{ZnO}$ supported material, the profiles do not change greatly, indicating that the only effect is to remove some of the adsorbate. Heating the $1 \% \mathrm{AuPd} / \mathrm{ZnO}$ in oxygen resulted in reaction of the benzyl alcohol and desorption of most of the products. The very weak remnant is clearly aromatic and probably a mixture of toluene and benzaldehyde. In contrast to $1 \% \mathrm{AuPd} / \mathrm{ZnO}$, where all of the reactions could be carried out on the same sample, it was necessary to prepare a separate sample for $1 \% \mathrm{AuPd} / \mathrm{TiO}_{2}$ since reaction occurs under anaerobic conditions. Benzyl alcohol was adsorbed on the catalyst; however, treatment with oxygen did not result in any change in the spectrum.

\section{Concluding comments}

It was found that benzyl alcohol undergoes competitive oxidative dehydrogenation, giving benzaldehyde, and disproportionation, to yield equimolar benzaldehyde and toluene, when treated with oxygen over an AuPd nanoparticulate catalyst supported on titania or carbon, but only oxidative dehydrogenation when the catalyst is supported on $\mathrm{MgO}$ or $\mathrm{ZnO}$. In situ spectroscopic examination of reaction mixtures have been undertaken in an attempt to identify intermediates and surface-bound species that would throw light on the mechanisms involved. ATR-IR examination yielded signals attributable only to species in the liquid phase and, under an oxygen atmosphere, these confirmed the support-dependent differences in behaviour of the catalysts, observed previously by conventional catalytic studies. In reactions catalysed by $1 \% \mathrm{AuPd} / \mathrm{TiO}_{2}$ under argon, however, the ATR signals attributed to benzaldehyde decreased with time at the reaction temperature $\left(120{ }^{\circ} \mathrm{C}\right)$ with a corresponding increase in the signal used as a measure of the benzyl alcohol remaining in the system. This deviation from expectation did not occur when $1 \% \mathrm{AuPd} / \mathrm{C}$ or $1 \% \mathrm{AuPd} /$ $\mathrm{MgO}$ were the catalysts. A number of possible explanations of this paradoxical behaviour have been considered, the favoured one being the analytical complication introduced by the equilibrium formation of the benzyl hemiacetal or more probably acetal of benzaldehyde on the relationship between signal intensity and concentration of benzaldehyde and benzyl alcohol. A DRIFTS investigation of the same reaction systems revealed only one signal that distinguished the behaviour of the acidic $\left(\mathrm{TiO}_{2}\right)$ and basic (ZnO) supports. Using $1 \% \mathrm{AuPd} / \mathrm{TiO}_{2}$ a carbonyl signal was observed at the unusually low frequency of $1655 \mathrm{~cm}^{-1}$. It has not proved possible to determine whether this arises from attachment of the carbonyl moiety to the metal through its carbonyl carbon or its carbonyl oxygen atom and thus it has not proved possible to discriminate between previously proposed modes of chemisorption of benzyl alcohol on the metal surface and hence on mechanisms for oxidative dehydrogenation. Inelastic neutron scattering has thrown somewhat greater light on the processes occurring at the catalyst surface. Benzyl alcohol appears to adsorb intact on the metal surface; a weak additional signal at $3210 \mathrm{~cm}^{-1}$ remains unassigned. It is clear, that the initial interaction of benzyl alcohol with the metal catalyst is not by benzylic $\mathrm{C}-\mathrm{H}$ cleavage, although this process could be involved subsequently, giving a transient surface species that is undetectable by the present technique. We have not found any direct spectroscopic evidence for the species shown in Scheme 1 for disproportionation; those mechanistic depictions remain merely rationalisations of the organic transformations that are helpful in understanding the results from earlier isotopic labelling experiments. It is clear that even using a range of in situ vibrational spectroscopies it has proved to be difficult to unravel some of the subtle details in this fascinating reaction and those techniques using shorter timescales for observation of reaction species need to be considered.

\section{Acknowledgements}

The authors thank the EPSRC for funding, the STFC Rutherford Appleton Laboratory for access to neutron beam facilities and Dr James Pritchard and Mr Scott Davies for their assistance during INS measurements. Computing resources (time on the SCARF computer used to perform the CASTEP calculations) was provided by STFC's e-Science facility. MS thanks the European Research Council (ERC) for awarding a Marie Curie Fellowship 
(IEF) for Career Development (Award No. 275755), while JPH would like to express gratitude to the German Research Foundation (DFG) (postdoctoral research grant Ho4579/1-1) and the Dutch National Research School Combination Catalysis (NRSC-Catalysis) for funding.

\section{References}

1 M. Sankar, N. Dimitratos, P. J. Miedziak, P. P. Wells, C. J. Kiely and G. J. Hutchings, Chem. Soc. Rev., 2012, 41, 8099-8139.

2 D. I. Enache, J. K. Edwards, P. Landon, B. Solsona-Espriu, A. F. Carley, A. A. Herzing, M. Watanabe, C. J. Kiely, D. W. Knight and G. J. Hutchings, Science, 2006, 311, 362-365.

3 G. L. Brett, Q. He, C. Hammond, P. J. Miedziak, N. Dimitratos, M. Sankar, A. A. Herzing, M. Conte, J. A. Lopez-Sanchez, C. J. Kiely, D. W. Knight, S. H. Taylor and G. J. Hutchings, Angew. Chem., Int. Ed., 2011, 50, 10136-10139.

4 L. Prati, F. Porta, D. Wang and A. Villa, Catal. Sci. Technol., 2011, 1, 1624-1629.

5 R. Garcia, M. Besson and P. Gallezot, Appl. Catal., A, 1995, 127, 165-176.

6 B. Bachiller-Baeza, A. Guerrero-Ruiz, P. Wang and I. Rodriguez-Ramos, J. Catal., 2001, 204, 450-459.

7 P. D. Zgolicz, V. I. Rodriguez, I. M. J. Vilella, S. R. de Miguel and O. A. Scelza, Appl. Catal., A, 2011, 392, 208-217.

8 A. M. Ruppert, K. Weinberg and R. Palkovits, Angew. Chem., Int. Ed., 2012, 51, 2564-2601.

9 V. Dal Santo, A. Gallo, A. Naldoni, M. Guidotti and R. Psaro, Catal. Today, 2012, 197, 190-205.

10 B. E. Solsona, J. K. Edwards, P. Landon, A. F. Carley, A. Herzing, C. J. Kiely and G. J. Hutchings, Chem. Mater., 2006, 18, 2689-2695.

11 J. M. Parera and J. N. Beltramini, J. Catal., 1988, 112, 357-365.

12 C. H. Bamford, C. F. H. Tipper and R. G. Compton, Liquid Phase Oxidation, Elsevier, Oxford, 1980.

13 R. A. Sheldon and J. K. Kochi, Metal-Catalysed Oxidations of Organic Compounds, Academic Press, New York, 1981.

14 M. Hudlicky, Oxidation in Organic Chemistry, American Chemical Society, Washington, DC, 1990.

15 T. Mallat and A. Baiker, Chem. Rev., 2004, 104, 3037-3058.

16 N. Dimitratos, J. A. Lopez-Sanchez, D. Morgan, A. F. Carley, R. Tiruvalam, C. J. Kiely, D. Bethell and G. J. Hutchings, Phys. Chem. Chem. Phys., 2009, 11, 5142-5153.

17 G. Kovtun, T. Kameneva, S. Hladyi, M. Starchevsky, Y. Pazdersky, I. Stolarov, M. Vargaftik and I. Moiseev, Adv. Synth. Catal., 2002, 344, 957-964.

18 S. Meenakshisundaram, E. Nowicka, P. J. Miedziak, G. L. Brett, R. L. Jenkins, N. Dimitratos, S. H. Taylor, D. W. Knight, D. Bethell and G. J. Hutchings, Faraday Discuss., 2010, 145, 341-356.
19 J. D. Grunwaldt and A. Baiker, Phys. Chem. Chem. Phys., 2005, 7, 3526-3539.

20 In Situ Spectroscopy of Catalyst, ed. B. M. Weckhuysen, American Scientific Publishers, California, 2004.

21 B. M. Weckhuysen, Chem. Commun., 2002, 97-110.

22 M. Sankar, E. Nowicka, R. Tiruvalam, Q. He, S. H. Taylor, C. J. Kiely, D. Bethell, D. W. Knight and G. J. Hutchings, Chem.-Eur. J., 2011, 17, 6524-6532.

23 C. Keresszegi, D. Ferri, T. Mallat and A. Baiker, J. Phys. Chem. B, 2005, 109, 958-967.

24 D. Ferri and A. Baiker, Top. Catal., 2009, 52, 1323-1333.

25 J. M. Andanson and A. Baiker, Chem. Soc. Rev., 2010, 39, 4571-4584.

26 S. Chilukoti, E. Widjaja, F. Gao, H. Zhang, B. G. Anderson, J. W. H. Niemantsverdriet and M. Garland, Phys. Chem. Chem. Phys., 2008, 10, 3535-3547.

27 J. G. Highfield, M. Prairie and A. Renken, Catal. Today, 1991, 9, 39-46.

28 J. G. Highfield, M. H. Chen, P. T. Nguyen and Z. Chen, Energy Environ. Sci., 2009, 2, 991-1002.

29 D. Ferri, M. S. Kumar, R. Wirz, A. Eyssler, O. Korsak, P. Hug, A. Weidenkaff and M. A. Newton, Phys. Chem. Chem. Phys., 2010, 12, 5634-5646.

30 P. C. H. Mitchell, S. F. Parker, A. J. Ramirez-Cuesta and J. Tomkinson, Vibrational spectroscopy with neutrons, with applications in chemistry, biology, materials science and catalysis, Singapore, 2005.

31 S. F. Parker, Handbook of Vibrational Spectroscopy, John Wiley \& Sons, New York, 2006.

32 S. F. Parker, D. Lennon and P. W. Albers, Appl. Spectrosc., 2011, 65, 1325-1341.

33 J. Zakzeski, R. J. H. Grisel, A. T. Smit and B. M. Weckhuysen, ChemSusChem, 2012, 5, 430-437.

34 J. Zakzeski, P. C. A. Bruijnincx and B. M. Weckhuysen, Green Chem., 2011, 13, 671-680.

35 I. P. Silverwood, N. G. Hamilton, A. McFarlane, R. M. Ormerod, T. Guidi, J. Bones, M. P. Dudman, C. M. Goodway, M. Kibble, S. F. Parker and D. Lennon, Rev. Sci. Instrum., 2011, 82, 1-7.

36 E. Cao, M. Sankar, E. Nowicka, Q. He, M. Morad, P. J. Miedziak, S. H. Taylor, D. W. Knight, D. Bethell, C. J. Kiely, A. Gavriilidis and G. J. Hutchings, Catal. Today, 2012, 203, 146-152.

37 M. Sankar, E. Nowicka, R. Tiruvalam, Q. He, S. H. Taylor, C. J. Kiely, D. Bethell, D. W. Knight and G. J. Hutchings, Chem.-Eur. J., 2011, 17, 6524-6532.

38 H. Zhao, J. Kim and B. E. Koel, Surf. Sci., 2003, 538, 147-159.

39 D. A. Prystupa, A. Anderson and B. H. Torrie, J. Raman Spectrosc., 1994, 25, 175-182.

40 S. K. Nayak, R. Sathishkumar and T. N. G. Row, CrystEngComm, 2010, 12, 3112-3118. 